\title{
Structure of noncoding RNA is a determinant of function of RNA binding proteins in transcriptional regulation
}

\author{
Takanori Oyoshi ${ }^{1}$ and Riki Kurokawa ${ }^{2^{*}}$
}

\begin{abstract}
The majority of the noncoding regions of mammalian genomes have been found to be transcribed to generate noncoding RNAs (ncRNAs), resulting in intense interest in their biological roles. During the past decade, numerous ncRNAs and aptamers have been identified as regulators of transcription. 6S RNA, first described as a ncRNA in $E$. coli, mimics an open promoter structure, which has a large bulge with two hairpin/stalk structures that regulate transcription through interactions with RNA polymerase. B2 RNA, which has stem-loops and unstructured singlestranded regions, represses transcription of mRNA in response to various stresses, including heat shock in mouse cells. The interaction of TLS (translocated in liposarcoma) with CBP/p300 was induced by ncRNAs that bind to TLS, and this in turn results in inhibition of CBP/p300 histone acetyltransferase (HAT) activity in human cells. Transcription regulator EWS (Ewing's sarcoma), which is highly related to TLS, and TLS specifically bind to Gquadruplex structures in vitro. The carboxy terminus containing the Arg-Gly-Gly (RGG) repeat domains in these proteins are necessary for cis-repression of transcription activation and HAT activity by the N-terminal glutaminerich domain. Especially, the RGG domain in the carboxy terminus of EWS is important for the G-quadruplex specific binding. Together, these data suggest that functions of EWS and TLS are modulated by specific structures of ncRNAs.
\end{abstract}

Keywords: noncoding RNA, EWS, TLS, B2 RNA, G-quadruplex, TERRA

\section{Introduction}

Gene silencing has emerged as one of the major functions of short double stranded noncoding RNAs (ncRNAs) that are generated by specific processing machinery. The mechanisms by which small ncRNAs, siRNAs and miRNAs, participate in RNAi pathway involved in gene silencing, mRNA stability and translation arrest have been extensively studied [1,2]. In contrast, regulatory functions of other classes of ncRNAs are much less well understood. Transcription is also regulated by other classes of ncRNAs, including long, single-stranded, polyadenylated RNA molecules. Recently, ncRNAs and synthetic RNA oligonucleotides (RNA aptamers) have been found to exert inhibitory

\footnotetext{
* Correspondence: rkurokaw@saitama-med.ac.jp

${ }^{2}$ Division of Gene Structure and Function Research Center for Genomic Medicine Saitama Medical University, 1397-1 Yamane, Hidaka-shi, SaitamaKen, Japan, Mail code 350-1241

Full list of author information is available at the end of the article
}

effects on transcription through inhibition of histone acetyltransferase (HAT). The inhibitory effect was achieved through blocking function of transcription machinery with conformational changes. In this review, we describe inhibitory mechanisms used by divergent ncRNAs and discuss common structures of these ncRNAs involved in regulation of transcription. Recently, a guanine-rich structure has been found to exert regulatory roles in eukaryotic transcription. Therefore, we also focus on regulatory functions of the guanine-rich structure in transcription.

6S RNA inhibits RNA polymerase II in E. coli 6S RNA was first describe as a ncRNA in E. coli [3]. 6S RNA mimics an open promoter structure and regulates transcription through interaction with RNA polymerase in bacterial cells [4]. The structure of 6S RNA shows a large bulge of two single strands between the stalk and the hairpin structures. Bacterial RNA polymerase is a

\section{Biomed Central}


multi-subunit enzyme consisting of a core enzyme and a specific subunit, forming the holoenzyme [5]. The 6S RNA sequence surrounding the bubble has contacts directly with both the $\sigma^{70}$ and $\beta / \beta$ ' polymerase subunits in the holoenzyme [6-8]. 6S RNA accumulates as cells reach the stationary phase of growth and mediates phase-specific change of RNA polymerase [4,9]. 6S RNA represses expression from a $\sigma^{70}$-dependent promoter during the stationary phase [4]. The binding of 6S RNA with RNA polymerase modulates the $\sigma^{70}$-holoenzyme activity. The binding of the $6 \mathrm{~S}$ RNA competes with binding of the RNA polymerase to the promoter regions. The bacterial RNA polymerase utilizes the $6 \mathrm{~S}$ RNA as a template and generates short (14- to 20-nt) RNA products that are initiated within the bubble $[6,10]$. The RNA products form a triplex-helix hybrid with the 6S RNA hairpin. This hybrid might destabilize the RNA polymerase-6S RNA complex, and rescue polymerase activity from the repressed status.

Reducing the size of the single-stranded region of $6 \mathrm{~S}$ RNA with deletion mutation destroys activity. The alteration of sequences to induce base-paring throughout the region of $6 \mathrm{~S}$ RNA also results in producing an inactive RNA, suggesting that the structure is crucial [8]. However, the enlargement of the overall size of the single-stranded DNA at the bulge region of 6S RNA had no effect on binding to RNA polymerase, indicating that there are not precise size requirements for the bulge region [8].

\section{B2 RNA represses transcription by RNA polymerase II in mouse cells}

B2 RNA is likely to be a eukaryotic counterpart of the bacterial 6S RNA and a small ncRNA of 178 nt transcribed by RNA polymerase III from short interspersed elements (SINEs). Expression of B2 RNA was increased in response to transformation by simian virus 40 and various stresses, including UV exposure, gamma radiation, and heat shock in mouse cell [11-20]. B2 RNA proposed to contribute to the repression of the transcription of house-keeping genes like actin and hexokinase II after treatment with heat-shock stress [14].

B2 RNA binds RNA polymerase and inhibits transcription [21]. Through this binding to RNA polymerase II, B2 RNA is incorporated into preinitiation complexes at promoters and inhibits transcription. The 70 nucleotides (nts) at the 5' end of B2 RNAs are evolutionarily conserved with tRNAs, and the 3' ends of B2 RNAs contain an A-rich sequence also conserved among all short interspersed elements, which are retrotransposons dispersed throughout the mouse genome with $\sim 350,000$ copies per cell [22]. Biochemical assay shows that the 5' region from 3 to 74 nts neither binds to polymerase nor represses transcription, whereas the region from 75 to
149 binds to RNA polymerase II and represses transcription [23]. Further deletion experiments revealed that the region from 81 to 131 , which contains a stemloop (81-97) and the unstructured single-stranded region (98-115), can be assembled into the preinitiation complexes and also represses transcription.

\section{ncRNAs and G-rich RNA binding to TLS}

It has been published that ncRNAs transcribed from the promoter regions of cyclin D1 gene (promoter-associated ncRNAs) have regulatory roles in transcription [24]. Evidence that the promoter-associated ncRNAs execute transcriptional regulation, has been recently provided by analysis of TLS (translocated in liposarcoma) [24]. TLS was initially identified as TLS-CHOP, the fusion protein arising from a chromosomal translocation [25,26]. TLS also has been found to be involved in numerous activities, including transcription control, mRNA processing and DNA repair [27-29].

Biochemical studies demonstrated that TLS could bind to $\mathrm{CBP} / \mathrm{p} 300$, which serve as essential coactivator for divergent species of transcription factors, for example, CREB, nuclear receptors, NF $\kappa \mathrm{B}$ and STAT transcription factors [30,31]. Their function of coactivator is mainly generated by their intrinsic histone acetyltransferase (HAT) activity [32,33]. Furthermore, TLS could strongly inhibit the CBP/p300 HAT activity on the core histones and other substrates [24].

It has been reported that synthetic RNA oligonucleotides bind to TLS through a consensus sequence GGUG [34]. Upon binding of GGUG RNA oligonucleotides (GGUG RNA), inhibitory activity of TLS against the $\mathrm{HAT}$ activity of CBP/p300 was enhanced [24]. Biochemical experiments showed that the carboxy terminus of TLS bound to GGUG RNA, whereas the $\mathrm{N}$ terminus was interacted with CBP. The $\mathrm{N}$ terminus of TLS alone has stronger inhibitory activity against the HAT than did the full-length TLS. Furthermore, the $\mathrm{N}$ terminus of TLS turned out to interact with the C terminus of TLS (Figure 1A). The lower inhibitory activity of the fulllength TLS might be the outcome of blocking the binding of the N-terminal domain of TLS with the HAT domain of $\mathrm{CBP} / \mathrm{p} 300$ through binding of the TLS C-terminus. TLS bound with GGUG RNAs induced its higher binding to $\mathrm{CBP} / \mathrm{p} 300$. These data suggest that the stronger inhibition of the HAT activity by TLS bound GGUG RNA results from bound of the C-terminus of TLS with GGUG RNA (Figure 1A) [34].

The interaction of TLS with CBP/p300 was stimulated by RNA oligonucleotides that binds to TLS, and this in turn resulted in inhibition of $\mathrm{CBP} / \mathrm{p} 300 \mathrm{HAT}$ activity (Figure 1B) [24]. Cell-based studies demonstrated that TLS could be recruited to and repress a subset of CREB target genes, including cyclin D1 and cyclin E1, by 


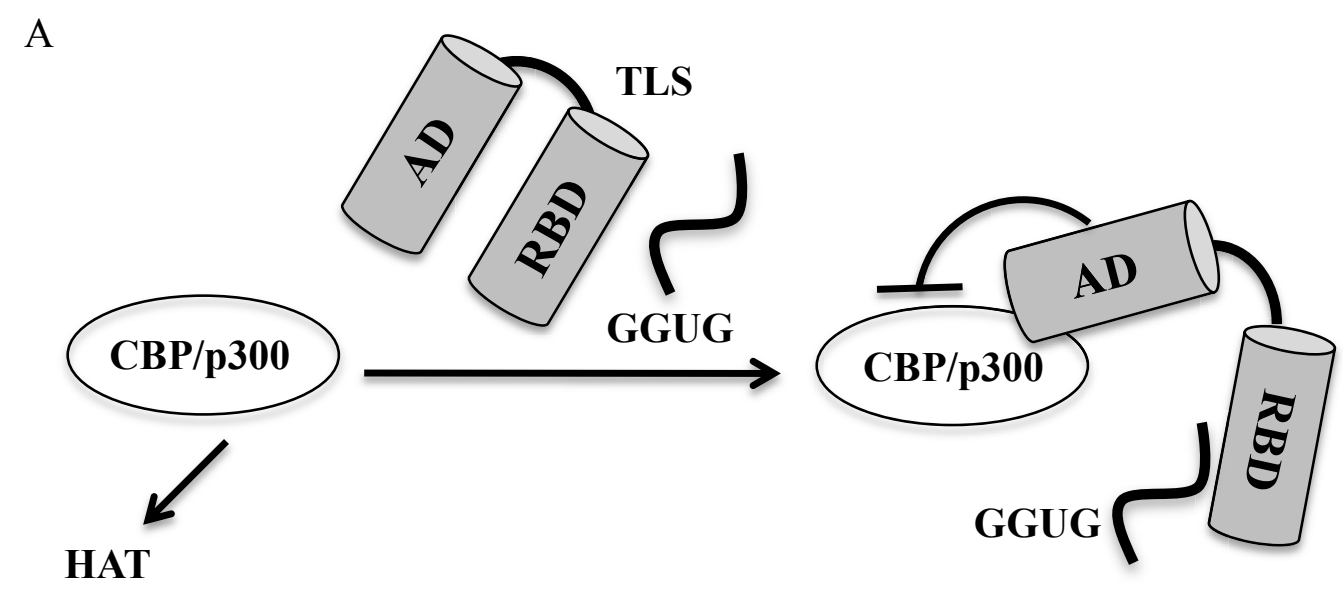

B

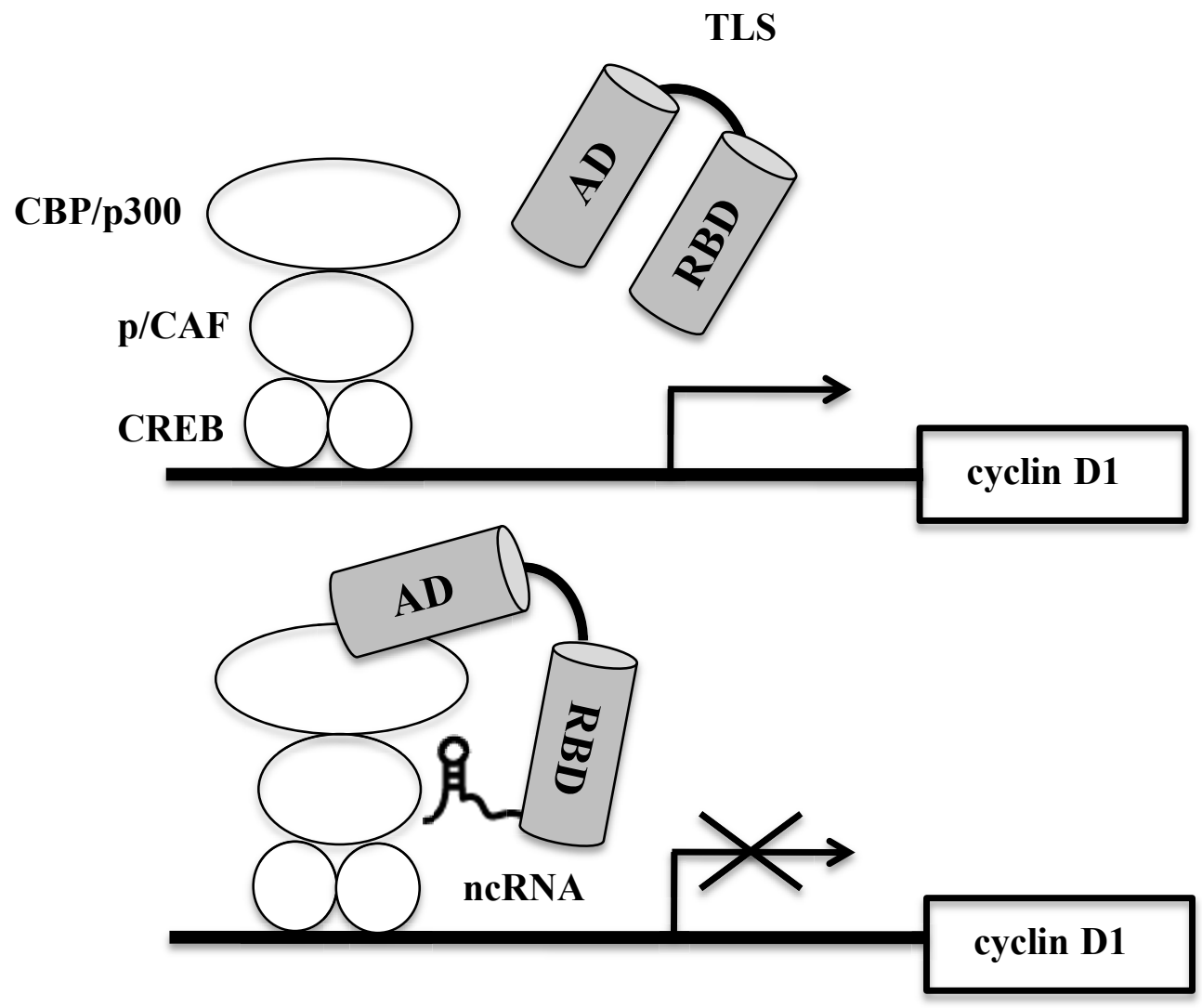

Figure 1 Mechanism of RNA-dependent histone acetyltransferase (HAT) activities regulated by TLS. (A) HAT regulation by TLS and GGUG. (B) Transcriptional regulation by TLS and ncRNAs. AD: activation domain, RBD: RNA binding domain, p/CAF: p300/CBP-associated factor.

reducing local histone acetylation. Intriguingly, recruitment of TLS appeared to be dependent on its binding to ncRNAs transcribed from promoter regions of the cyclin D1 gene. Furthermore, transcription of these promoter-associated ncRNAs was induced by ionizing radiation, enhancing TLS recruitment and reducing cyclin D1 expression. Taken together, these findings provide the basis for a model in which the promoter- associated ncRNAs recruit TLS to the cyclin D1 promoter [24]. The interaction of these ncRNAs with TLS induces recruitment of TLS to the promoter region of cyclin D1, and also a conformational change of TLS. This conformational change of TLS enables it to interact with $\mathrm{CBP} / \mathrm{p} 300$ and to inhibit their HAT activities.

RNA bearing Guanine-rich sequences is able to fold into a G-quadruplex structure with cyclic Hoogsteen 
A

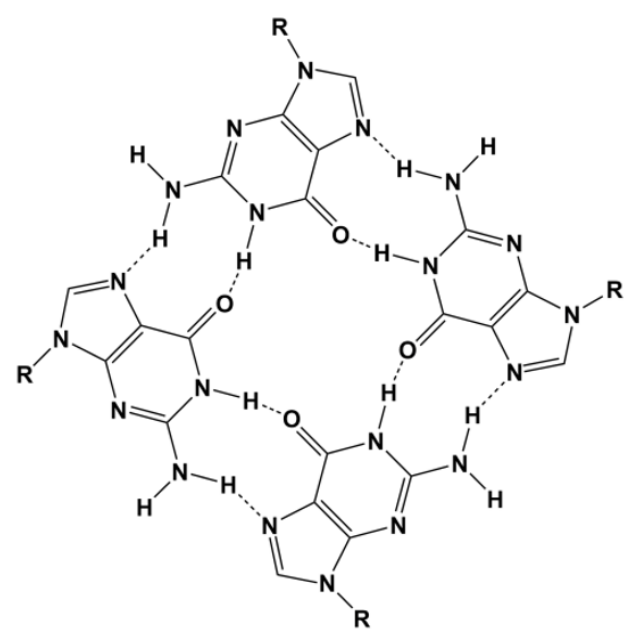

G-tetrad

B

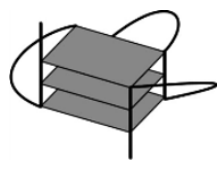

TERRA

\section{UUAGGGUUAGGGUUAGGGUUAGGG}

Figure 2 Structural features of human telomeric repeat containing RNA (TERRA) formed into G-quadruplex. (A) Structure of G-tetrad consisting of G-quadruplex. (B) G-quadruplex structure and sequences of TERRA.

base pairs of four guanine bases (G-tetrads; Figure 2A) $[35,36]$. The formation of the G-quadruplex is stabilized by the presence of monovalent cations (e.g., $\mathrm{Na}^{+}, \mathrm{K}^{+}$), which are positioned in the center of the structure and coordinated by the electron-rich carbonyl oxygens. The NMR structure of human telomeric repeat containing RNA (TERRA) $r(U U A G G G)_{4}$ with $\mathrm{K}^{+}$has been solved as the G-quadruplex structure in vitro and the structure of TERRA in living cells has been confirmed as G-quadruplex by a lights-switching pyrene probe (Figure 2B) [37].

TERRA is a large non-coding RNA in fungi and animals and works as a direct inhibitor of human telomerase, forming an integrated component of telomeric heterochromatin in cellular nuclei [38-41]. TLS strongly binds to TERRA via G-quadruplex structure in vitro [42]. Purification of the human telomeric chromatin using proteomics technology indicated that TLS is one component of telomere binding protein goups [43]. TLS forms a complex with the heterogeneous nuclear ribonucleoprotein A1 (hnRNP A1) which contains the four RNA recognition motifs and the RGG domain in the Cterminal domain and binds to TERRA and human telomeric DNA [44-46]. hnRNP A1 modulates telomere length and displaces the replication protein A (RPA) for protection of binding of telomeres 1 (POT 1) to telomeric DNA.

TERRA, G-quadruplex RNA, binds to transcriptional factor EWS

EWS is homologous to TLS and TAF15. These three proteins form the TET family (Figure 3 ). The current knowledge of EWS (Ewing's sarcoma) has been provided mainly from analysis of dominant oncogenes that arise due to chromosomal translocations in which EWS is fused to a variety of cellular transcription factors $[28,47,48]$. The EWS fusion proteins are potent transcription activators that require the EWS N-terminal domain and the C-terminal DNA-binding domain contributed by fusion partners [49-54]. For instance, a fusion gene EWS-ATF1 is a potent constitutive activator of ATF-dependent promoters [55]. The N-terminus of EWS binds directly to a subunit (hsRPB7) of RNA polymerase II and the interaction is thought to be important for transactivation [56].

The N-terminal regions of the TET proteins contain the glutamine-rich domain that is a common structure of transcription activation domain, while the $\mathrm{C}$-terminal 


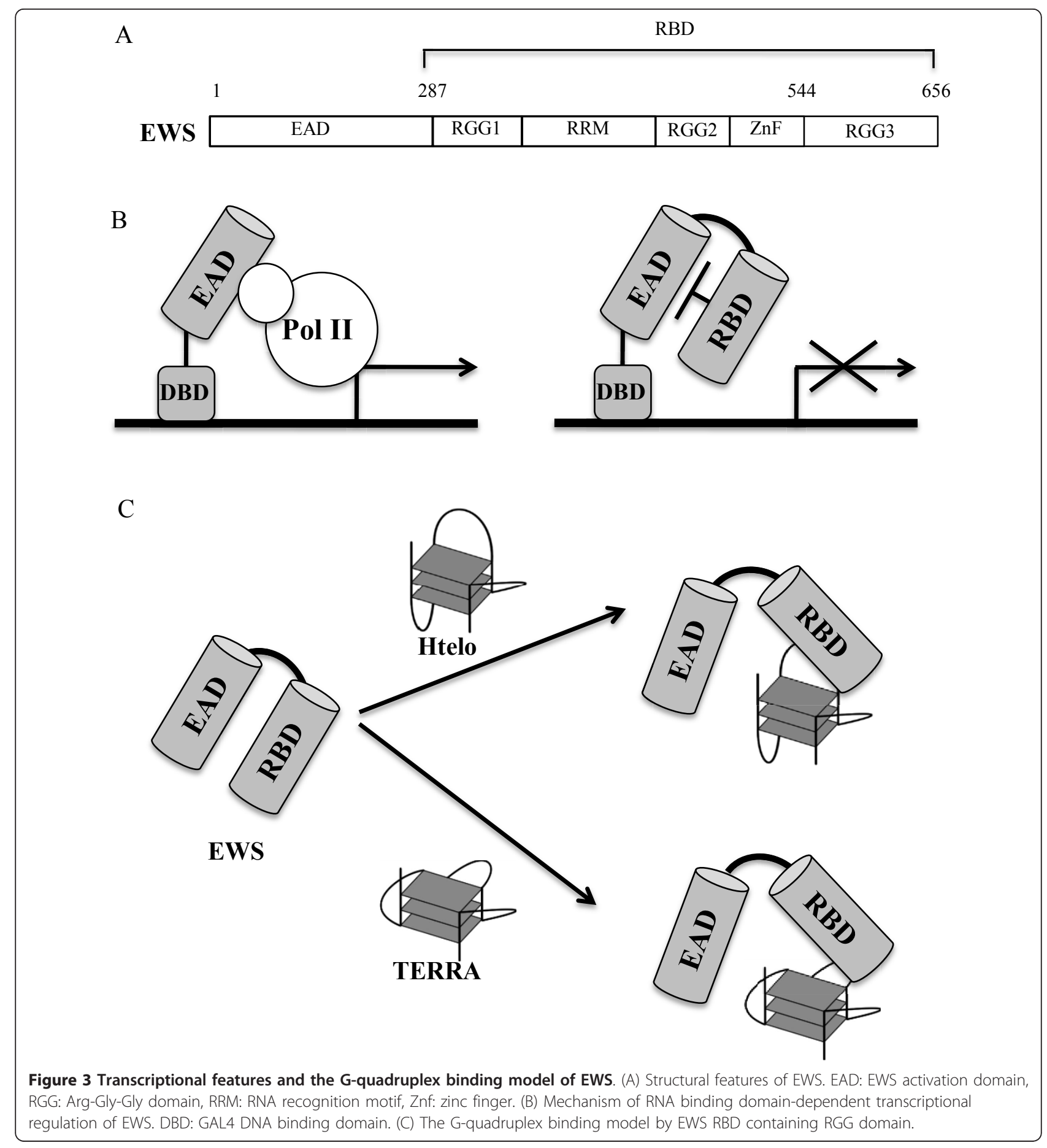

half of the TET proteins contains a series of RNA binding regions, including an RNA recognition motif (RRM), a $\mathrm{C}_{2} \mathrm{C}_{2}$ zinc finger ( $\mathrm{ZnF}$ ) and three Arg-Gly-Gly (RGG) repeat domains (Figure 3A) [57,58]. The RGG domain within the carboxy terminus of EWS is necessary for cis-repression of transcription induced by the N-terminus of the glutamine-rich domain (Figure 3B) $[58,59]$. The transcription repression might result from the carboxy-terminal RGG domain that blocks interaction between the $\mathrm{N}$-terminus of the glutamine-rich domain and hsRPB7.

Similar to TLS, EWS could bind to TERRA through the G-quadruplex in a structure-specific manner (Figure $3 C)[60,61]$. Binding experiments showed that the carboxy-terminal RGG domain of EWS specifically bound to G-quadruplex RNA, whereas the proteins containing 
the N-terminal of the glutamine-rich domain, RRM, ZnF and other RGG domains did not [60]. The carboxyterminal RGG domain of EWS contributes not only to the binding to G-quadruplex RNA but also that to Gquadruplex DNA binding. EWS binds preferentially to G-quadruplexes with the longer loops. The electrophoresis mobility shift assay using EWS with G-quadruplexes containing abasic sites instead of nucleotides in the loops indicates that the carboxy-terminal RGG domain of EWS recognizes the phosphate backbone of the loops in G-quadruplexes. The findings could contribute to analyzing the nucleic acids binding protein that selectively target the G-quadruplex structures. Enzymic methylation of Arg by protein arginine $N$-methyltransferase (PRMT) 3 reduced the binding RGG domain of EWS to G-quadruplexes but increased its binding to single-strand DNA and RNA. PRMT1 (a homologue of PRMT3) reduced transcriptional activity of EWS through nuclear exclusion of EWS by methylation of arginine residues [62]. It suggests that the regulation of nucleic acids structure specific binding by EWS might play an important role in regulating the transcriptional activity. Substitution of the phenylalanines in the RGG domain in EWS eliminated almost completely G-quadruplex bindings. These findings indicate that the phenylalanines and guanidinium groups of the arginines in RGG domain of EWS are important for binding of EWS to the G-quadruplex. Moreover, not only Arg-Gly-Gly repeats sequences but also Arg and Pro rich sequence in RGG domain of C-terminus are important for its specific binding to G-quadruplex. The RGG domain has been widely observed at divergent kinds of RNA-binding proteins $[63,64]$. These data might contribute to understanding of the nucleic acids binding specificity of RNAbinding proteins containing RGG domains.

\section{Conclusions}

Folding of RNA into divergent structures is constrained by specific RNA sequences under physiological conditions. Recent analyses revealed that several ncRNAs form specific conformations in sequence-and structurespecific manners, mimicking an open promoter structures and G-quadruplex structures. In living cells, specific three-dimensional structures of these ncRNAs could contribute to regulation of transcription. It remains however unclear whether a role of EWS in transcription is fixed by its ability to target a specific RNA structure. Janknecht et al. reported that overexpression of EWS in RK13 and AKR cells leads to activation of the c-fos, Xvent-2, and ErbB2 promoters, while EWS did not bind to double-stranded DNAs in these promoters [65]. These data suggest that EWS might function as a transcriptional regulator upon its binding with structurespecific RNAs. On the other hand, Kingston and
Dejardin purified the human telomeric chromatins using proteomics technology with isolated chromatin segments and, found that TLS binds to telomeres [43]. Telomeres are transcribed form the telomeric C-rich strand, giving rise to TERRA $\mathrm{r}(\mathrm{UUAGGG})_{4}$ which forms G-quadruplex in vivo. TLS might bind to TERRA and regulate transcription of TERRA.

\section{List of abbreviations}

ncRNAs: noncoding RNAs; TLS: translocated in liposarcoma; EWS: Transcriptional factor Ewing's sarcoma; HAT: histone acetyltransferase; TERRA: telomeric repeat containing RNA.

\section{Acknowledgements}

The author thanks Ms. R. Tanji for her making figures and format of the manuscript. The authors thank Dr. Glass for his valuable advice. This work was supported by Takeda Science Foundation, the Naito foundations, Astellas Foundation for Research on Metabolic Disorders Foundation and also by Grant-in-Aid for Scientific Research (B: nos22390057), Grant-in-Aid for Challenging Exploratory Research (nos23659461), Grant-in-aid for "Support Project of Strategic Research Center in Private Universities" from the Ministry of Education, Culture, Sports, Science and Technology to Saitama Medical University Research Center for Genomic Medicine, the Sasakawa Scientific Research Grant from The Japan Science Society and a Grant-in-Aid for Young Scientists (B: 20750130) from the Ministry of Education, Science, Sports, and Culture of Japan.

\section{Author details}

${ }^{1}$ Department of Chemistry, Faculty of Science, Graduate School of Science, Shizuoka University, 836 Oya, Suruga, Shizuoka 422-8529, Japan. Division of Gene Structure and Function Research Center for Genomic Medicine Saitama Medical University, 1397-1 Yamane, Hidaka-shi, Saitama-Ken, Japan, Mail code 350-1241.

\section{Authors' contributions}

TO and RK made substantial contributions to conception, design and been involved in drafting the manuscript. RK has given final approval of the version to be published. Each author has participated sufficiently in the work to take public responsibility for appropriate portions of the content. TO and RK read and approved the final manuscript.

\section{Competing interests}

The authors declare that they have no competing interests.

Received: 6 September 2011 Accepted: 3 January 2012 Published: 3 January 2012

\section{References}

1. Fire A, Xu S, Montgomery MK, Kostac SA, Driver SE, Mello CC: Potent and specific genetic interference by double-stranded RNA in Caenorhabditis elegans. Nature 1998, 391:806-811.

2. Filipowicz W, Bhattacharyya SN, Sonenberg N: Mechanisms of posttranscriptional regulation by microRNAs: are the answers in sight? Nat Rev Genet 2008, 9:102-114.

3. Brownlee GG: Sequence of 6S RNA of E. coli. Nat New Biol 1971, 229:147-149.

4. Wassarman KM, Storz G: $6 S$ RNA regulates E. coli RNA polymerase activity. Cell 2000, 101:613-623.

5. Gruber TM, Gross CA: Multiple $\sigma$ subunits and the partitioning of bacterial transcription space. Annu Rev Microbiol 2003, 57:441-466.

6. Gildehaus N, Neusser T, Wurm R, Wagner R: Studies on the function of the riboregulator 6S RNA from E. coli: RNA polymerase binding, inhibition of in vitro transcription and synthesis of RNA-directed de novo transcripts. Nucleic Acids Res 2007, 35:1885-1896.

7. Barrick JE, Sudarsan N, Weinberg Z, Ruzzo WL, Breaker RR: 6S RNA is a widespread regulator of eubacterial RNA polymerase that resembles an open promoter. RNA 2005, 11:774-784. 
8. Trotochaud AE, Wassarman KM: A highly conserved $6 \mathrm{~S}$ RNA structure is required for regulation of transcription. Nat Struct Mol Biol 2005, 12:313-319.

9. Trotochaud AE, Wassarman KM: $6 \mathrm{~S}$ RNA function enhances long-term cell survival. J Bacteriol 2004, 186:4978-4985.

10. Wassarman KM, Saecker RM: Synthesis-mediated release of a small RNA inhibitor of RNA polymerase. Science 2006, 314:1601-1603.

11. Aleman C, Roy-Engel AM, Shaikh TH, Deininger PL: Cis-acting influences on Alu RNA levels. Nucleic Acids Res 2000, 28:4755-4761.

12. Jang KL, Latchman DS: The herpes simplex virus immediate-early protein ICP27 stimulates the transcription of cellular Alu repeated sequences by increasing the activity of transcription factor TFIIIC. Biochem J 1992 284:667-673.

13. Fornace AJ Jr, Alamo I Jr, Hollander MC, Lamoreaux E: Induction of heat shock protein transcripts and B2 transcripts by various stresses in Chinese hamster cells. Exp Cell Res 1989, 182:61-74.

14. Allen TA, Von Kaenel S, Goodrich JA, Kugel JF: The SINE-encoded mouse B2 RNA represses mRNA transcription in response to heat shock. Nat Struct Mol Biol 2004, 11:816-821.

15. Liu WM, Chu WM, Choudary PV, Schmid CW: Cell stress and translational inhibitors transiently increase the abundance of mammalian SINE transcripts. Nucleic Acids Res 1995, 23:1758-1765.

16. Fornace AJ Jr, Mitchell JB: Induction of B2 RNA polymerase III transcription by heat shock: enrichment for heat shock induced sequences in rodent cells by hybridization subtraction. Nucleic Acids Res 1986, 14:5793-5811.

17. Li T, Spearow J, Rubin CM, Schmid CW: Physiological stresses increase mouse short interspersed element (SINE) RNA expression in vivo. Gene 1999, 239:367-372

18. Price BD, Calderwood SK: Heat-induced transcription from RNA polymerases II and III and HSF binding activity are co-ordinately regulated by the products of the heat shock genes. I Cell Physiol 1992, 153:392-401

19. White RJ, Stott D, Rigby PW: Regulation of RNA polymerase III transcription in response to Simian virus 40 transformation. EMBO J 1990, 9:3713-3721.

20. Rudin CM, Thompson CB: Transcriptional activation of short interspersed elements by DNA-damaging agents. Genes Chromosomes Cancer 2001, 30:64-71.

21. Espinoza CA, Allen TA, Hieb AR, Kugel JF, Goodrich JA: B2 RNA binds directly to RNA polymerase II to repress transcript synthesis. Nat Struct Mol Biol 2004, 11:822-829.

22. Kramerov DA, Vassetzky NS: Short retroposons in eukaryotic genomes. Int Rev Cytol 2005, 247:165-221.

23. Espinoza CA, Goodrich JA, Kugel JF: Characterization of the structure, function, and mechanism of B2 RNA, and ncRNA repressor of RNA polymerase II transcription. RNA 2007, 13:583-596.

24. Wang X, Arai S, Song X, Reichart D, Du K, Pascual G, Tempst P, Rosenfeld MG, Glass CK, Kurokawa R: Induced ncRNAs allosterically modify RNA-binding proteins in cis to inhibit transcription. Nature 2008, 454:126-130

25. Crozat A, Aman P, Mandahl N, Ron D: Fusion of CHOP to a novel RNAbinding protein in human myxoid liposarcoma. Nature 1993, 363:640-644.

26. Zinszner $\mathrm{H}$, Sok J, Immanuel $\mathrm{D}$, Yin $Y$, Ron D: TLS (FUS) binds RNA in vivo and engages in nucleo-cytoplasmic shuttling. J Cell Sci 1997, 110:1741-1750.

27. Uranishi H, Tetsuka T, Yamashita M, Asamitsu K, Shimizu M, Itoh M, Okamoto T: Involvement of the pro-oncoprotein TLS (translocated in liposarcoma) in nuclear factor-kappaB p65-mediated transcription as a coactivator. J Biol Chem 2001, 276:13395-133401.

28. Ron D: TLS-CHOP and the role of RNA-binding proteins in oncogenic transformation. Curr Top Microbiol Immunol 1997, 220:131-142.

29. Bertrand P, Akhmedov AT, Delacote F, Durrbach A, Lopez BS: Human POMp75 is identified as the pro-oncoprotein TLS/FUS: both POMp75 and POMp75 and POMp100 DNA homologous pairing activities are associated to cell proliferation. Oncogene 1999, 18:4515-4521.

30. Chrivia JC, Kwok RP, Lamb N, Hagiwara M, Montminy MR, Goodman RH: Phosphorylated CREB binds specifically to the nuclear protein CBP. Nature 1993, 365:855-859.
31. Kurokawa R, Kalafus D, Ogliastro MH, Kioussi C, Xu L, Torchia J, Rosenfeld MG, Glass CK: Differential use of CREB binding proteincoactivator complexes. Science 1998, 279:700-703.

32. Ogryzko W, Schiltz RL, Russanova V, Howard BH, Nakanani Y: The transcriptional coactivators $\mathrm{p} 300$ and CBP are histone acetyltransferases. Cell 1996, 87:953-959.

33. Bannister AJ, Kouzarides T: The CBP co-activator is a histone acetyltransferase. Nature 1996, 384:641-643.

34. Lerga A, Hallier M, Delva L, Orvain C, Gallais I, Marie J, Moreau-Gachelin F: Identification of an RNA Binding Specificity for the Potential Splicing Factor TLS. J Biol Chem 2001, 276:6807-6816.

35. Xu Y, Kaminaga K, Komiyama M: G-quadruplex formation by human telomeric repeats-containing RNA in $\mathrm{Na}^{+}$solution. J Am Chem Soc 2008, 130:11179-11184

36. Martadinata H, Phan AT: Structure of propeller-type parallel-stranded RNA G-quadruplexes, formed by human telomeric RNA sequences in $\mathrm{K}^{+}$ solution. J Am Chem Soc 2009, 131:2570-2578.

37. Xu Y, Suzuki Y, Ito K, Komiyama M: Telomeric repeat-containing RNA structure in living cells. Proc Natl Acad Sci USA 2010, 107:14579-14584.

38. Azzalin CM, Reichenbach P, Khoriauli L, Giulotto E, Lingner J: Telomeric repeat containing RNA and RNA surveillance factors at mammalian chromosome ends. Science 2007, 318:798-801.

39. Schoeftner S, Blasco MA: Developmentally regulated transcription of mammalian telomeres by DNA-dependent RNA polymerase II. Nat Cell Biol 2008, 10:228-236.

40. Redon S, Reichenbach P, Lingner J: The non-coding RNA TERRA is a natural ligand and direct inhibitor of human telomerase. Nucleic Acids Res 2010, 38:5797-5806.

41. Deng Z, Norseen J, Wiedmer A, Riethman H, Lieberman PM: TERRA RNA binding to TRF2 facilitates heterochromatin formation and ORC recruitment at telomeres. Mol Cell 2009, 35:403-413.

42. Takahama K, Kino K, Arai S, Kurokawa R, Oyoshi T: Identification of RNA binding specificity for the TET-family proteins. Nucleic Acids Symp Ser 2008, 52:213-214.

43. Dejardin J, Kingston RE: Purification of proteins associated with specific genomic loci. Cell 2009, 136:175-186.

44. LaBranch H, Dupuis S, Ben-David Y, Bani MR, Wellinger RJ, Chabot B: Telomere elongation by hnRNP A1 and a derivative that interacts with telomeric repeats and telomerase. Nat Genet 1998, 19:199-202.

45. Lopez de Silanes I, Stagno d'Alcontres M, Blasco MA: TERRA transcripts are bound by a complex array of RNA-binding proteins. Nat Commun 2010, 1:33.

46. Flynn RL, Centore RC, O'Sullivan RJ, Rai R, Tse A, Songyang Z, Chang S, Karlseder J, Zou L: TERRA and hnRNPA1 orchestrate an RPA-to POT1 switch on telomeric single-stranded DNA. Nautre 2011, 471:532-536.

47. May WA, Denny CT: Biology of EWS/FLI and related fusion genes in Ewing's sarcoma and primitive neuroectodermal tumor. Curr Top Microbiol Immunol 1997, 220:143-150.

48. Rauscher FJ III: Chromosome translocation-mediated conversion of a tumor suppressor gene into a dominant oncogene: fusion of EWS1 to WT1 in desmoplastic small round cell tumors. Curr Top Microbiol Immunol 1997, 220:151-162

49. Brown AD, Lopez-Terrada D, Denny C, Lee KA: Promoters containing ATFbinding sites are de-regulated in cells that express the EWS/ATF1 ontogeny. Oncogene 1995, 10:1749-1756.

50. Fujimura Y, Ohno T, Siddique H, Lee L, Rao VN, Reddy ES: The EWS-ATF-1 gene involved in malignant melanoma of soft parts with $t(12 ; 22)$ chromosome translocation, encodes a constitutive transcriptional activator. Oncogene 1996, 12:159-167.

51. May WA, Lessnick SL, Braun BS, Klemsz M, Lewis BC, Lunsford LB, Hromas R, Denny CT: The Ewing's sarcoma EWS/FLI-1 fusion gene encodes a more potent transcriptional activator and is a more powerful transforming gene than FLI-1. Mol Cell Biol 1993, 13:7393-7398.

52. Ohno T, Rao VN, Reddy ES: EWS/Fli-1 chimeric protein is a transcriptional activator. Cancer Res 1993, 53:5859-5863.

53. Ohno T, Ouchida M, Lee L, Gatalica Z, Rao VN, Reddy ES: The EWS gene, involved in Ewing family of tumors, malignant melanoma of soft parts and desmoplastic small round cell tumors, codes for an RNA binding protein with novel regulatory domains. Oncogene 1994, 9:3087-3097. 
54. Sanchez-Garcia I, Rabbitts TH: Transcriptional activation by TAL1 and FUSCHOP proteins in aute malignancies as a result of chromosomal abnormalities. Proc Natl Acad Sci USA 1994, 91:7869-7873.

55. Pan S, Ming KY, Dunn TA, Li KK, Lee KA: The EWS/ATF1 fusion protein contains a dispersed activation domain that functions directly. Oncogene 1998, 16:1625-1631.

56. Petermann R, Mossier BM, Aryee DN, Khazak V, Golemis EA, Kover H: Oncogenic EWS-Fli1 interacts with hsRPB7, a subunit of human RNA polymerase II. Oncogene 1998, 17:603-610.

57. Delattre O, Zucman J, Plougastel B, Desmaze C, Melot T, Peter M, Kovar H, Joubert I, de Jong P, Rouleau G, Aurias A, Thomas G: Gene fusion with an ETS DNA-binding caused by chromosome translocation in human tumours. Nature 1992, 359:162-165.

58. Li KK, Lee KA: Transcription activation by the Ewing's Sarcoma (EWS) oncogene can be cis-repression by the EWS RNA-binding domain. J Biol Chem 2000, 275:23053-23058.

59. Alex D, Lee KA: RGG-boxes of the EWS oncoprotein repress a range of transcriptional activation domains. Nucleic Acids Res 2005, 33:1323-1331.

60. Takahama K, Kino K, Arai S, Kurokawa R, Oyoshi T: Identification of Ewing's sarcoma protein as a G-quadruplex DNA-and RNA-binding protein. FEBS J 2011, 278:988-998

61. Takahama K, Sugimoto C, Arai S, Kurokawa R, Oyoshi T: Loop lengths of Gquadruplex structures affect the G-quadruplex DNA binding selectivity of the RGG motif in Ewing's Sarcoma. Biochemistry 2011, 50:5369-5378.

62. Araya N, Hiraga H, Kako K, Arao Y, Kato S, Fukamizu A: Transcriptional down-regulation through nuclear exclusion of EWS methylated by PRMT1. Biochem Biophys Res Commun 2005, 329:653-660

63. Burd CG, Dreyfuss G: Conserved structures and diversity of functions of RNA-binding proteins. Science 1994, 265:615-621.

64. Law WJ, Cann KL, Hicks GG: TLS, EWS and TAF15: a model for transcriptional integration of gene expression. Brief Funct Genomic Proteomic 2006, 5:8-14.

65. Rossow KL, Janknecht R: The Ewing's sarcoma gene product functions as a transcriptional activator. Cancer Res 2001, 61:2690-2695.

doi:10.1186/2045-3701-2-1

Cite this article as: Oyoshi and Kurokawa: Structure of noncoding RNA is a determinant of function of RNA binding proteins in transcriptional regulation. Cell \& Bioscience 2012 2:1.

\section{Submit your next manuscript to BioMed Central and take full advantage of:}

- Convenient online submission

- Thorough peer review

- No space constraints or color figure charges

- Immediate publication on acceptance

- Inclusion in PubMed, CAS, Scopus and Google Scholar

- Research which is freely available for redistribution

Submit your manuscript at www.biomedcentral.com/submit
Biomed Central 